\title{
Mısır Ekim Alanlart ve Dane Veriminin Uzaktan Algılama ve Hybrid-Maize Bitki Modeli ile Belirlenmesi
}

\author{
Idris $\boldsymbol{U S L U} \boldsymbol{U}^{*}(\mathbb{D}$ \\ Zerrin ÇELIK ${ }^{2}$ \\ Sinan $\operatorname{ARAS}^{3}$ \\ Vural KARAG $\ddot{U} L^{4}$ \\ Merve ETÖZ $Z^{5}$ \\ Aslı ÖZDARICI OK ${ }^{6}$ \\ 1,2,3,4,5 Uluslararası Tarımsal Araștırma ve Eğitim Merkezi Müdürlüğü, Menemen-İzmir/TURKEY
${ }^{6}$ Ankara Hacı Bayram Veli Üniversitesi Tapu Kadastro Yüksekokulu, Ankara/TURKEY
}

\author{
${ }^{1}$ https://orcid.org/0000-0003-4505-8348 \\ ${ }^{3}$ https://orcid.org/0000-0002-7935-9205 \\ ${ }^{2}$ https://orcid.org/0000-0002-9478-9414 \\ ${ }^{4}$ https://orcid.org/0000-0001-8654-6036 \\ ${ }^{5}$ https://orcid.org/0000-0002-6398-361X \\ ${ }^{6}$ https://orcid.org/0000-0002-3430-0541 \\ *Corresponding author (Sorumlu yazar): idris.uslu@tarimorman.gov.tr \\ Received (Geliş tarihi): 10.05.2021Ａccepted (Kabul tarihi): 07.10.2021
}

\begin{abstract}
ÖZ: Tarımsal üretimin çevre koşulları ile olan sıkı ilişkisi ve günümüz dünyasında tarımsal ürünlere olan talep artışı bitkisel üretimin sistematik, hızlı ve güvenilir şekilde izlenmesini gerekli kılmaktadır. Uzaktan algılama; ürün izleme, ekim alanları ve bitki veriminin tahmin edilmesinde önemli bir teknoloji olarak karşımıza çıkmaktadır. Bu çalışmada, 2020 yılında Menemen Ovası'nda yaygın olarak yetiștirilen önemli bitkilerden biri olan mısır için ekim alanları ve dane verimi incelenmiștir. Araștırmada Göktürk-2 uydusu ile görüntülenen misır ekim alanları segment tabanlı sinıflandırma yöntemiyle \%86,7 genel doğruluk ve \%73,3 Kappa oranlarıla tespit edilmiştir. Yerden ölçülen dane misır verimi ve uydu verisinden üretilen NDVI değerleri arasındaki regresyon modeli değerleri $R^{2}=0,77$ belirleme katsayısı ve $P \leq 0,01$ hata düzeyinde elde edilmistir. Regresyon modeli yöntemi ile araştırma alanında geniş alanlardaki misır verimi tahmin edilmiştir. Bunun yanında potansiyel verimin incelenmesinde HybridMaize bitki modeli kullanılmıştır. Çalışma ile bitki modeli ile hesaplanan potansiyel verim değerleri ile gerçek verim değerlerinin karşılaştırılabileceği ve parsel bazlı değişimlerin incelenmesinde kullanılabileceği sonucuna ulaşılmıştır.
\end{abstract}

Anahtar kelimeler: Ürün izleme, verim tahmini, uzaktan algılama, Hybrid-Maize, uydu görüntüsü.

\section{Determination of Maize Planting Areas and Grain Yields Using Remote Sensing and Hybrid-Maize Crop Model}

ABSTRACT: The close relationship of agricultural production with environmental conditions and the increase in demand for agricultural products in today's world, make it necessary to monitor crop production in a reliable, fast and systematic manner. In this sense, remote sensing is a valuable technology that enables monitoring and crop area and yield estimations in agricultural studies. This research studied the area sown and grain yields of maize, a common crop on the Menemen Plain. In the research, maize fields were classified in object based classification manner by Göktürk-2 taken in 2020 with $86.7 \%$ overall accuracy and $73.3 \%$ Kappa value. The values of determination coefficient and significance level of the regression model which was obtained between measured maize grain yield and NDVI values of the satellite data were, $R^{2}=0.77$ and $P \leq 0.01$, respectively. The regression model method was used to calculate the yield of wider areas in the research. In addition, potential yield of the region was estimated by a crop model, Hybrid-Maize. With this study, it has been concluded that the potential yield values calculated with the plant model can be compared with the actual yield values and can be used in the analysis of plot-based changes.

Keywords: Crop monitoring, yield estimation, remote sensing, Hybrid-Maize, satellite image. 


\section{GíRiș}

Tarımsal üretimde bitkisel ürünlerin ekim alanları ile verim miktarlarının sistematik, hızlı ve güvenilir şekilde belirlenmesi önemli bir konudur. Özellikle iklim değişikliğinin etkilerini yaşadığımız son dönemlerde yoğun olarak yetiştiriciliği yapılan bitkilerin ekim alanı ve verim tahmininin önemi artmıştır. Gelişen bilişim teknolojileri sayesinde uydu verileri ve araziden toplanan verilerle kabul edilebilir doğruluklarda hem üretim deseni belirlenebilmekte, hem de önemli ürünlerin verim durumları saptanabilmektedir (Satir ve Berberoglu, 2016). Uydu verileri ve bitki büyüme modelleri araştırmacılara bu gibi tahminlemeler açısından kolaylık sağlamaktadır (Schultes ve ark., 2013). Bu veriler, üretim planlanması ve ülkesel tarım politikalarının oluşturulmasında önem arz etmektedir. $\mathrm{Bu}$ tür çalışmalarla desteklenmiş tarımsal politikalar bir ülkenin doğal kaynaklarının etkin bir şekilde kullanımında önemli rol oynayacaktır.

Uydu verilerinden üretilen vejetasyon indeksleri ile bitkinin yaprak alanı indeksi ve klorofil yoğunluğu arasında iyi bir ilișki yaygın olarak bulunsa da, bitkinin biyo kütlesi, azot içeriği ve verim özellikleri için hem konum ve hem de mevsimlere göre bir kalibrasyon genel olarak gerekli olmaktadır (Jones ve Vaughan, 2010). Bitki modelleri tüm durumlarda aynı başarı derecesini sergilememektedir. $\mathrm{Bu}$ bakımdan, son kullanıcının bir modelin varsayımlarını anlayıp yeni bir ortam için uygunluğunu belirlemesi önemlidir (Steinberg ve Steinberg, 2015).

$\mathrm{Bu}$ çalışmada NDVI ile geniş alanlarda yetiştirilen misır alanlarının ve veriminin sistematik, hizlı ve yüksek doğrulukta belirlenmesi ve aynı zamanda Hybrid-Maize bitki simülasyon modeli ile potansiyel mısır veriminin hesaplanması amaçlanmıştır.

\section{MATERYAL ve METOT}

\section{MATERYAL}

Araştırma Menemen Ovası'nda yürütülmüştür (Şekil 1). Bu amaçla bitki yetiştiriciliğine ait veriler için Uluslararası Tarımsal Araştırma ve Eğitim Merkezi (UTAEM) arazisinde bir gözlem parseli oluşturulmuştur. Bitki yetiştiriciliği verileri ve uydu görüntüsü verisi araştırmanın birinci materyalini ve üretici şartlarını ortaya koyabilmek amacıyla anket formu aracılığıyla üreticilerden elde edilen veriler araştırmanın bir diğer materyalini oluşturmaktadır.

Menemen Ovas $18^{\circ} 26^{\prime}$ ile $38^{\circ} 40^{\prime}$ kuzey enlemleri ve $26^{\circ} 40^{\prime}$ ile $27^{\circ} 07^{\prime}$ doğu boylamları arasında yer alan 33.545 ha alanı kapsamaktadır. Denizden yüksekliği 10,3 m'dir. Ova topraklarının büyük bir kısmı orta ve orta-ağır bünyeli olup eski Gediz yatağ $\breve{1}$ kenarında genel olarak hafif, batıya doğru gidildikçe ağır karakter kazanmaktadır. Menemen Ovası alüvyal araziler ile koluviyal dağ eteklerini kapsamaktadır (Anonim, 1971).

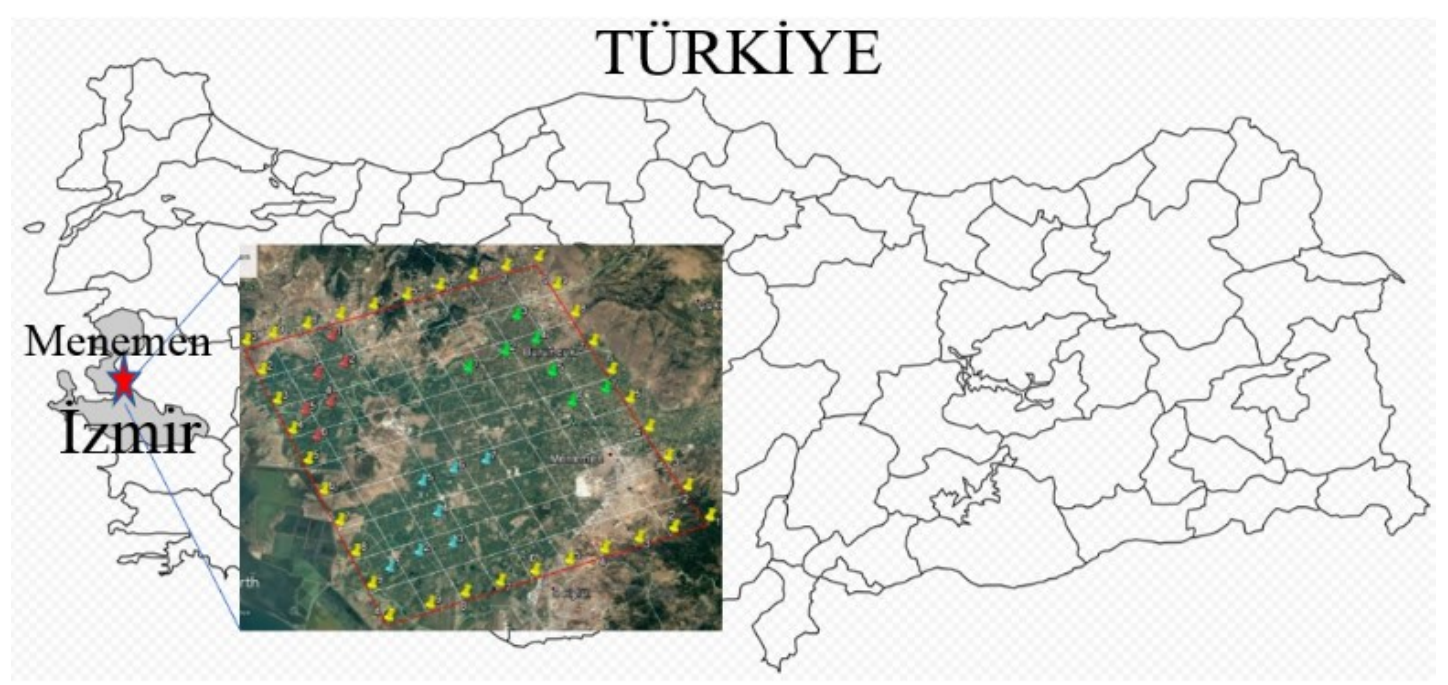

Şekil 1. Çalışma alanı.

Figure 1. Study area. 
Ege Bölgesi, makro iklim özelliği yönünden Akdeniz iklim tipine girmektedir. Yazları sıcak ve kurak, kışları ise 1lık ve yağışlı bir özellik göstermektedir. Menemen'de uzun yıllar ortalama iklim verilerine göre; toplam y1llık yağgş $535,3 \mathrm{~mm}$ olup bunun \%50,2'si kış, \%24,3'ü ilkbahar, \%23,4'ü sonbahar ve \%2,2'si yaz aylarında düşmektedir. Ortalama sicaklık $16,9^{\circ} \mathrm{C}$ olup, en sicak ay ortalaması $27^{\circ} \mathrm{C}$ ile Temmuz ve en soğuk ay ortalamas $17,8^{\circ} \mathrm{C}$ ile Ocak ayıdır. Ortalama nispi nem $\% 57,8$ olup en yüksek \%67,3 ile Aralık, en düşük ise \%46,7 ile Temmuz ayında gerçekleşmiştir. Toplam buharlaşma $1516,5 \mathrm{~mm}$, en düşük aylık buharlaşma $44,1 \mathrm{~mm}$ ile Aralık ayında, en yüksek buharlaşma ise 259,4 $\mathrm{mm}$ ile Temmuz ayında gerçekleşmiştir (Anonim, 2020).

Menemen ilçesinde tarım alanları 225000 da olup tane misır yetiştiriciliği genellikle I. ürün olarak yapılmaktadır. Tane mısır I. ürün ekilişi 2020 yılı için 3136 da olarak gerçekleşmiştir (Anonim, 2021). Ekim alanı ve üretim bakımından Menemen Ovası'nda önde gelen bitkilerden biri olması nedeniyle, araştırmada I. ürün tane mısır bitkisi seçilmiştir.

$\mathrm{Bu}$ araştırmada Göktürk-2 uydusuna ait 01 Temmuz 2020 tarihli 1 adet görüntü kullanılmıştır. Göktürk-2 uydu ve görüntü özellikleri Çizelge 1'de verilmiştir. Uydu pankromatik, mavi, yeşil, kırmızı ve yakın kızılötesi (B, G, R, NIR) spektral bantlara sahip olup, pankromatik (PAN) çözünürlüğü 2,5 $\mathrm{m}$, diğer bantların çözünürlüğü ise $5 \mathrm{~m}$ 'dir.

Çizelge 1. Göktürk-2 uydu ve görüntü özellikleri (Teke ve ark., 2016).

Table 1. Gokturk-2 satellite image and technical characteristics (Teke et al., 2016).

\begin{tabular}{|c|c|}
\hline $\begin{array}{l}\text { Yörünge: } \\
\text { Orbit: }\end{array}$ & $\begin{array}{l}685 \text { km irtifa, Güneş Eş } \\
\text { zamanlı, } \\
\text { (Yükselen Nokta Eşzamanı } \\
\text { 10:30) }\end{array}$ \\
\hline $\begin{array}{l}\text { Görüntüleme bantları } \\
\text { Imaging bands }\end{array}$ & $\begin{array}{l}\text { Pankromatik, Kırmızı, Yeşil, } \\
\text { Mavi, Yakın kızılötesi }\end{array}$ \\
\hline $\begin{array}{l}\text { PAN çözünürlük } \\
\text { PAN resolution }\end{array}$ & $2,5 \mathrm{~m}$ \\
\hline $\begin{array}{l}\text { Diğer bantlar çözünürlük } \\
\text { MS resolution }\end{array}$ & $5 \mathrm{~m}$ \\
\hline $\begin{array}{l}\text { Görüntü genişliği } \\
\text { Image width }\end{array}$ & $20 \mathrm{~km}$ \\
\hline $\begin{array}{l}\text { Azami şerit uzunluğu } \\
\text { Maximum swath length }\end{array}$ & $640 \mathrm{~km}$ \\
\hline
\end{tabular}

Bitki modeli olarak, Agrometeorolojik simülasyon modellerinden Hybrid-Maize (HM) modeli kullanılmıştır. HM bitki simülasyon modeli, mısıra özel bitki büyüme ve gelişimi eşitlikleri ile CERESMaize modeli, fotosentez ve solunum eşitlikleri ile ise INTERCOM ve WOFOST modellerinde bulunan iki yaklaşımı birleştirmektedir. Modelde sıcaklığa bağlı fenolojik gelişim, dikey büyümeyle birleștirilen fotosentez, organlara özgü büyüme solunumu ve sicaklığa duyarlı devam ettirme solunumu tanımlanmıştır. Brüt fotosentez üretimi, büyüme solunumu ve devam ettirme solunumunun modele dahil edilmesi HM modelini çevre koşullarına CERES-Maize modelinden daha hassas yapmaktadır. HM tahmin doğruluğunu azaltmadan daha az genotipik parametreye gereksinim duyar. Yapılan çalışmalarda yaprak alanı, kuru madde birikimi, tane verimi ve hasat indeksi parametrelerinde ölçülen ve simüle edilen değerler arasında yüksek uyum belirlenmiştir (Yang ve ark., 2004). Model girdileri; tohum çeşidi, ekim tarihi, fizyolojik oluma kadar olan toplam gün derece, püskül çıkarma dönemine kadar toplam gün derece (eşik sıcaklık $10^{\circ} \mathrm{C}$ ), ekim sıklığ 1 , ekim derinliği, sulama rejimi (ekim zamanı toprak nemi, sulama zamanı, su miktarı ve hasat zamanı toprak nemi), günlük meteoroloji ölçümleri (minimum sıcaklık $\left({ }^{\circ} \mathrm{C}\right)$, maksimum sicaklik $\left({ }^{\circ} \mathrm{C}\right)$, Global Radyasyon (watt $\mathrm{m}^{-2}$ )'dir (Schultes ve ark., 2013). Model, çıktı olarak olası tüm senaryoları en iyi, \%75, en kötü $\% 25$ olarak hesaplayarak sonucu ortalama olarak vermektedir. Kullanılan model ile sezon içi hesaplamalar yapabildiği gibi en son püskül çıkarmadan iki hafta sonrası için nihai tahmin elde edilebilmektedir. Model çiftçilerin ve yayımcıların kolayca kullanabileceği şekilde geliştirilmiştir (Yang ve ark., 2016).

\section{METOT}

Çalışma yöntemi; gözlem parselinden verilerin elde edilmesi, uydu görüntüsü ile ekim alanları ve verim tahmini ve bitki modeliyle potansiyel verim tahminini kapsamaktadır (Şekil 2). Her bir basamağa ilişkin detaylar aşağıda verilmektedir.

\section{Gözlem parseli}

Mısır bitkisinin gelişimini izlemek ve gerçekleşen verimi ölçmek için 14 da büyüklügünde gözlem 
parseli oluşturulmuştur. Ekim işlemi 21 Nisan 2020 tarihinde $25 \mathrm{~kg}$ DAP taban gübresi uygulanan parsele $70 \mathrm{~cm}$ sira arasi ve $18 \mathrm{~cm}$ sira üzeri mesafede $4 \mathrm{~cm}$ derinliğe yapılmıştır. Gözlem parselinde misır gelişiminde varyasyon oluşturmak amaciyla farklı seviyelerde üst gübre uygulanmıştır. Üst gübre uygulamas1 03 Haziran 2020 tarihinde \%50, $\% 100$ ve $\% 150$ oranlarına uygun olarak $15,30,45$ $\mathrm{kg} \mathrm{da} \mathrm{da}^{-1}$ üre uygulaması şeklindedir. Şekil 3 'de görülen mavi noktaların olduğu alt bölgede $\% 150$, yeşil noktaların olduğu alt bölgede $\% 100$, beyaz noktaların olduğu alt bölgede ise $\% 50$ oranında üre gübresi uygulanmıştır. Koçan kurdu ilacı 05 Haziran 2020, 1. sulama 25 Haziran 2020, 2. sulama 08 Temmuz 2020 ve 3 . sulama 22 Temmuz 2020 tarihinde uygulanmıştır. Gözlem ve ölçümler bir deneme deseni planında değil, tüm parselde belirlenen noktalarda yapılmıştır (Battude ve ark., 2016; Satir ve Berberoglu, 2016; Schultes ve ark., 2013) (Şekil 3).

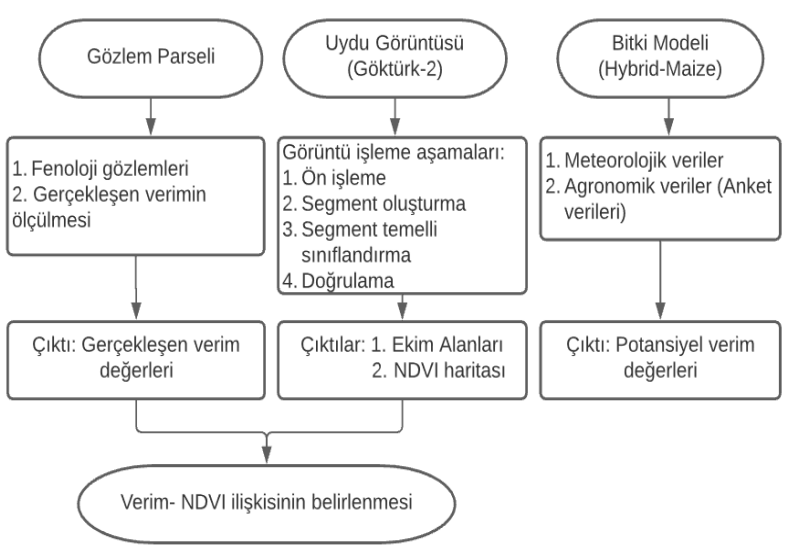

Şekil 2. Verim tahmininde veri kaynakları ve işlem aşamaları. Figure 2. Data sources and processing stages in yield estimation.

\section{Bitki gözlemleri}

Misır gözlem parselinde fenolojik gözlem yapılmıştır. Hasat zamanı uydu görüntüsünde bir piksel büyüklüğü alana denk gelen $25 \mathrm{~m}^{2}$ örnekleme alanı içinden rastgele $1 \mathrm{~m}^{2}$ lik 2 tekrarlı olarak tane verimi ölçümü yapılmış ve ortalamaları alınmıştır. Ana kütle aritmetik ortalamasının standart hatasını küçültmede örnek sayısının örnek büyüklüğünden daha etkili olması nedeniyle (Konuk 2016), araştırmada gözlem parselinde bulunan 60 gözlem noktasından 1 metrekarede yer alan bitkilerin tamamı 2 tekrarlı olarak örneklenmiştir (Battude ve ark., 2016).

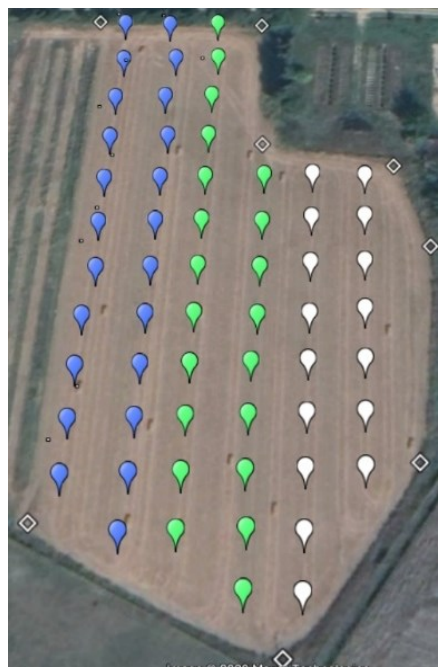

Şekil 3. Gözlem parseli.

Figure 3. The observation plot.

Görüntü sınıflamasında; mısır bitkisi ile karıştığı bildirilen domates (Turker ve Ozdarici, 2011) ve pamuk (Sarı ve ark., 2007) ile araştırma alanında yaygın bulunan bitkilerden yonca dikkate alınmıştır. $\mathrm{Bu}$ bitkilerin yetiştirildiği 150'şer parselden koordinat değerleri alınarak görüntü sınıflandırma sonucunun doğrulanmasında kullanılmıştır.

\section{Uydu görüntüsü ile ekim alanlarının sınıflandırılması}

Mısır ekim alanları uydu görüntüsünün segment tabanlı sınıflandırılması ile belirlenmiştir. Bunun için Göktürk-2 uydu görüntüsünün mavi, yeşil, kırmızı ve infrared bantları önce ana bileşenler analizi yapılarak birleştirilmiş, ardından segmentlere (nesnelere) ayrılmıştır. Spektral bantların ana bileşenler analizi yöntemi ile birleştirilmesinin nedeni; kullanılan segmentasyon algoritmasının çalışma prensibine bağlı olarak segmentlerin etkili şekilde tanımlanabilmesidir. Segment tabanlı görüntü sınıflandırması temel olarak iki aşamada uygulanmaktadır: Segmentasyon - nesne çıkartımı ve görüntü sinıflandırma. i) Segmentasyon - nesne çıkartımı: Segmentasyon kavramı, görüntüyü oluşturan en küçük görüntü elemanı olan piksellerin komşuluk ve benzerlik kriterlerine göre gruplara ayrılarak homojen yapıdaki nesnelere dönüştürme işlemidir. Araştırmada segmentlere ayırma yöntemi olarak sınır tabanlı segmentasyon yöntemi uygulanmıştır. $\mathrm{Bu}$ yöntemde önce uç değerlere sahip pikseller belirlenir ve segment boyunca belirlenen maksimum pikseller çeşitli 
takip algoritmalarıyla başlangıç noktasına gelinceye kadar tespit edilerek segmenti çevreleyen sınırlar ortaya çıkarılır (Ok, 2017). Genel segmentasyon eşitliği:

$\mathrm{S}_{f}=w_{\text {color }} \cdot h_{\text {color }}+\left(1-w_{\text {color }}\right) \cdot h_{\text {shape }} \quad$ Eşitlik (1) şeklindedir.

Eşitlikte $h_{\text {color }}$ renk kriteri, $w_{\text {color }}$ renk ağırlık faktörü, $\mathrm{h}_{\text {shape }}$ ise şekil kriteridir. Kullanıcı tarafından belirlenen renk ve şekil katsayısı $0 \leq w_{\text {color }} \leq 1$ aralığındadır (Jensen, 2016).

Araştırmada segmentler uydu görüntüsünün mavi, yeşil, kırmızı ve yakın kızıl ötesi bantları ana bileşenler analizi ile elde edilen katsayılarıyla ağırlıklandırılarak, ağırlık ortalama katsayısı, komşuluk benzerlik oranları ve ağırlık varyans katsayısına göre yapılmıştır (Egberth ve Nilsson 2010). İdeal segment ayrımı elde edilen sınıflandırma sonuçlara göre belirlenmiştir.

ii) Sınıflandırma: Sinıflandırma, görüntüyü oluşturan benzer spektral yansıma özelliğine sahip piksellerin algoritmalar yardımıyla benzer sinıflara ayrilması işlemidir. Segment tabanlı görüntü sinıflandırma işleminde ise görüntü segmentlerine ait bütünleşik bilgiler değerlendirilmektedir. $\mathrm{Bu}$ sayede segmenttabanlı sınıflandırma yaklaşımı, piksel tabanlı doku bilgisine göre genellikle daha fazla siniflama doğruluğu potansiyeline sahip olmaktadır. Sinıflama işleminin doğruluğunu belirlemede genel doğruluk, kullanıcı doğruluğu ve üretici doğruluğunu içeren hata matrisi ve Kappa İstatistiği yaygın olarak kullanılmaktadır (Ok, 2017).

Çalışmanın bir önceki aşamada elde edilen segmentler, araștırma alanından seçilen üçer adet domates, misır, pamuk ve yonca segmentleriyle en çok benzerlik yöntemine göre sınıflandırılmıştır (Sarı ve ark., 2007; Ozdarici Ok ve Akyurek, 2012).

\section{Uydu görüntüsü ile verim tahmini}

Araştırmada, uydu verisiyle yer gözlemleri birleştirilerek verim tahmin haritası oluşturulmuştur. Bunun için uydu görüntüsünden elde edilen Normalize Edilmiş Fark Bitki Örtüsü İndeksi (segmantasyon) ile gözlem parselinden ölçülen verimler arasındaki ilişkinin yüksek güvenilirlikte bir regresyon denklemi elde edilmesi amaçlanmıştır (Şekil 2). NDVI, bir pikselde bitki örtüsü miktarını belirlemeye yönelik tasarımlanmış en yaygın oransal (NDVI= (Yakın Kızılötesi Bant Kırmızı Bant) / (Yakın Kızılötesi Bant - Kırmızı Bant)) yöntemdir (Ok, 2017). Vejetasyona ait mevsim içi ve yıllar arası gelişim ve canlılık uydu görüntülerinden elde edilen NDVI indeksi yardımıyla izlenebilmektedir. Bu bakımdan, NDVI önemli bir vejetasyon indeksidir (Jensen, 2016). NDVI değerleri vejetasyon için $0-1$ aralığındadır ve bitki türü ile vejetasyonun toprağı kaplama oranından büyük oranda etkilenir (Jones ve Vaughan, 2010).

Basit doğrusal regresyonun hesaplanmasında $R$ programı (stat paketi) ve Python (pandas, numpy paketleri) programlarından yararlanılmıştır. Veriler işlenirken kötü kaldıraç noktaları ve etkili gözlemler "Cook uzaklığı" yöntemine göre R programında belirlenmiştir (Yorulmaz, 2016). Modelin çapraz doğrulamasında Python programı (sklearn.model_selection) paketi kullanılmıştır. Regresyonun başarısı $k$-katlı çapraz geçerleme yöntemi ile değerlendirilmiştir. Bu yöntemde veri kümesi $k$ kümeye bölünür. Her defasında bir küme geçerleme kümesi, geriye kalan $k-1$ küme ise öğrenme kümesi olarak kullanılır ve bu işlem $k$ defa kullanılır. Böylece öğrenme, geçerli ayrımı $k$ kez tekrar edilmiş ve modelin geçerliliği daha sağlam bir biçimde sınanmış olur (Arslan, 2019).

\section{Üretici verilerinin derlenmesi ve bitki modelinde kullanımı}

Modelin test edilebilmesi amaciyla 2020 y1linda araştırma alanında yer alan 75 üretici parseline ait parsel koordinatları ve yetiştiricilik bilgilerine ilişkin bilgiler hazırlanan yarı yapılandırılmış soru formu aracilığıyla yüz yüze görüşme tekniği ile gerçekleştirilmiştir. Araştırma kapsamında anket yapılan üreticiler ve onlara ait parseller çiftçi kayıt sistemi (ÇKS) listesi üzerinden rastgele seçilerek belirlenmiştir. Örnekleme için parsel sayısı, sonlu ana kitle için (317 tane misır parseli) \%95 güven aralığ 1 ve 0,10 hata payı ile 75 olarak belirlenmiştir. Örnek sayısının belirlenmesinde kullanılan eşitlik aşağıdaki gibidir:

$\mathrm{n}=\mathrm{N} \mathrm{S}^{2} \mathrm{t}^{2} /(\mathrm{N}-1) \mathrm{d}^{2}+\mathrm{S}^{2} \mathrm{t}^{2}$

Eşitlik (2)

Eşitlikte:

$\mathrm{n}=$ Örnek hacmi,

$\mathrm{N}=$ Toplam birim sayıs1, 
$\mathrm{S}=$ Standart sapma,

$\mathrm{t}=$ Güven sinırı,

$\mathrm{d}=$ Kabul edilebilir hata (Oğuz ve Karakayac1, 2017).

Araştırmada üretici parselleri ile gözlem parseli arasında kullanılan girdiler ve yetiştiricilik işlemlerinin birbiriyle aynı olması öngörülmemiştir. Anket çalışmasında tohum çeşidi, ekim tarihi, ekim sıklığı, ekim derinliği, sulama rejimi (kullanılan gübreler ve miktarı, sulama sayısı, su miktarı ve hasat zamanı) ve parsel verimine ilişkin veriler değerlendirilmiştir. Üretici parsellerine ilişkin kullanılan girdiler ve yetiştiricilik bilgilerinden yararlanılarak bitki modeli aracıllı̆̆ ile potansiyel verimler hesaplanmış ve üretici şartlarında gerçekleşen verimler ile karşılaştırılarak modelin tahminlemesi test edilmiştir.

\section{BULGULAR ve TARTIŞMA}

\section{BULGULAR}

\section{Uydu görüntüsü ile mısır ekim alanlarının belirlenmesi}

Misır alanlarının sınıflandırılması amacıyla kullanılan segmentasyon algoritmasi yoluyla uydu görüntüsünden segmentler elde edilmiştir. Nihai segmentler uydu görüntüsünün $\mathrm{B}, \mathrm{G}, \mathrm{R}, \mathrm{NIR}$ bantları ana bileşen analizi ile elde edilen $(0,85$; $0,14 ; 0,61 ; 0,03)$ katsayılarıyla ağırlıklandırılarak, $3 \times 3$ pencere boyutu ile 0,5 ağırlık ortalama katsayısı, 0,5 ve 10 komşuluk benzerlik oranları ve $0,5,1,1,5$ ve 2 ağırlık varyans katsayıları ile oluşturulmuştur. Elde edilen sinıflandırma sonuçlarına göre 0 benzerlik oranı ve 0,5 varyans ağırlık katsayısı ile elde edilen segmentler test edilen diğer parametrelere göre daha yüksek sınıflama başarısı göstermiştir (Çizelge 2).

Elde edilen segmentler, araştırma alanından seçilen üçer adet domates, misır, pamuk ve yonca segmentleriyle en çok benzerlik yöntemiyle sinıflandırılmıştır. Sonuçlar misır ve diğer bitkilerin oluşturduğu hata matrisi ve Kappa değeri ile ifade edilmiştir. Elde edilen sonuçlar Çizelge 3 'te verilmiştir. Buna göre mısır alanlarının sinıflandırılmasında kullanıcı doğruluğu $\% 84$, üretici doğruluğu \%90,7, genel doğruluk \%86,7 ve Kappa indeksi \% 73,3 olarak hesaplanmıştır.
Çizelge 2. Göktürk-2 görüntüsü sınıflandırma sonuçları.

Table 2. Classification results of Gokturk-2 image.

\begin{tabular}{lc}
$\begin{array}{l}\text { Sinıflandırma parametreleri } \\
\text { (Benzerlik oranı, ağılık varyans katsayısı) }\end{array}$ & Misır (\%) \\
$\begin{array}{l}\text { Classification parameters } \\
\text { (Similarity tolerance, weight variance factor) }\end{array}$ & Maize (\%) \\
\hline $0-0,5$ & 84 \\
$0-1,0$ & 78 \\
$0-1,5$ & 76,6 \\
$0-2,0$ & 78,6 \\
$5-1,0$ & 58,6 \\
$5-1,5$ & 73,3 \\
$10-1,0$ & 69,3 \\
$10-1,5$ & 73,3 \\
$10-2.0$ & 72,6 \\
\hline
\end{tabular}

Araştırmada gözlem parselinde ölçülen verim değerleri ile NDVI değerleri arasında basit doğrusal regresyon elde edilmiştir. Regresyonun performans değerleri 30 serbestlik derecesinde, hata oranı $\mathrm{P}<0,01$ ve $\mathrm{R}^{2}=0,77$ şeklinde hesaplanmıştır (Şekil 4). Regresyon modelinin çapraz doğrulama sonucu elde edilen $\mathrm{R}^{2}$ değerleri: $(0,82$; $0,47 ; 0,540,90 ; 0,83)$ ve ortalamas1 0,71 olarak gerçekleşmiştir. Şekil 4'te bulunan regresyon eşitliği NDVI haritasına uygulanarak gözlem parselinin Şekil 5'te görülen dane verim haritası elde edilmiştir. Buna göre parseli oluşturan piksellerin ortalaması parselin ortalama verimini (766 $\mathrm{kg} \mathrm{da}^{-1}$ ) göstermektedir. Parsel ortalama veriminin düşük olması üst gübreleme ile oluşturulan verim farklılıklarından kaynaklanmaktadır. Yüksek (\%150 Üre) ve düşük (\%50 Üre) uygulanan bölgelerde verim düşük olmuştur. Aynı eşitlik daha geniş alanlarda yetiştirilen misır bitkisinin verim tahmini için daha büyük bir NDVI haritasına uygulandığında Şekil 6'daki verim haritası elde edilmiştir.

Bitki modelinde girdi olarak kullanılan üretici parselleri ve gözlem parseline ait mısır çeşit özellikleri, ekim zamanı, ekim sıklığı ve iklim verileri kullanılarak potansiyel verimler hesaplanmıştır (Çizelge 4). Üretici parsellerine ait ortalama verimler $1272,7+/-137,8 \mathrm{~kg} \mathrm{da}^{-1}$ ve bitki modeliyle hesaplanan verim değerleri 1481,8 +/$68,8 \mathrm{~kg} \mathrm{da}^{-1}$ t-testi ile karşılaştırılmıştır. Buna göre, model tahmin değerlerinin istatistikî olarak 0,95 önem derecesinde daha yüksek olduğu görülmüştür. 
Çizelge 3. Göktürk-2 görüntüsü hata matrisi.

Table 3. Confusion matrix of Gokturk-2 image.

\begin{tabular}{|c|c|c|c|c|}
\hline & $\begin{array}{l}\text { Misır } \\
\text { Maize }\end{array}$ & $\begin{array}{l}\text { Diğerleri } \\
\text { Others }\end{array}$ & $\begin{array}{c}\text { Toplam } \\
\text { Total }\end{array}$ & $\begin{array}{l}\text { Kullanıcı Doğruluğu (\%) } \\
\text { (\%) User's accuracy }\end{array}$ \\
\hline $\begin{array}{l}\text { Misır } \\
\text { Maize }\end{array}$ & 126 & 24 & 150 & 84,00 \\
\hline $\begin{array}{l}\text { Diğerleri } \\
\text { Others }\end{array}$ & 14 & 136 & 150 & 90,66 \\
\hline $\begin{array}{l}\text { Toplam } \\
\text { Total }\end{array}$ & 140 & 160 & 300 & \\
\hline $\begin{array}{l}\text { Üretici doğruluğu (\%) } \\
\text { (\%) Producers accuracy }\end{array}$ & 90 & 85 & $\begin{array}{c}\text { Genel doğruluk (\%) } \\
\text { (\%) Overall accuracy } \\
86,66\end{array}$ & $\begin{array}{c}\text { Kappa indeksi (\%) } \\
(\%) \text { Kappa index } \\
73,33\end{array}$ \\
\hline
\end{tabular}

\section{Verim tahmini}
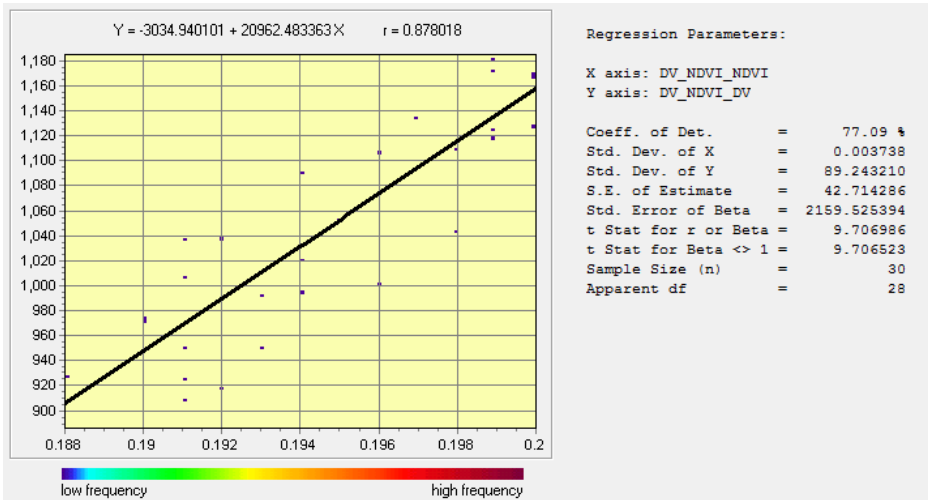

Şekil 4. Dane verimi ve NDVI arasında belirlenen basit doğrusal regresyon eğrisi ve değişkenleri.

Figure 4. Simple linear regression line and parameters of yield and NDVI.

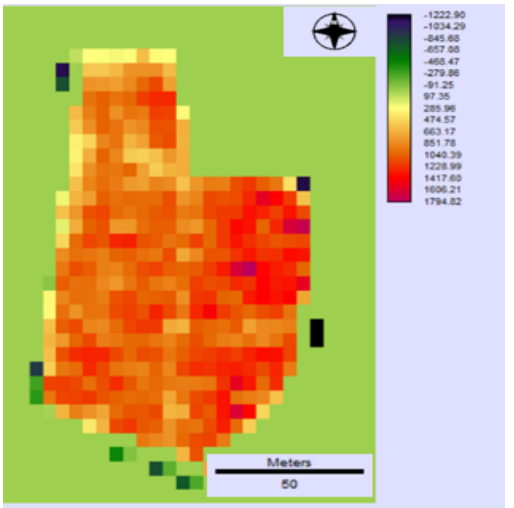

Şekil 5. Gözlem parseli mısır verim haritası. Figure 5. Yield map of observation plot.

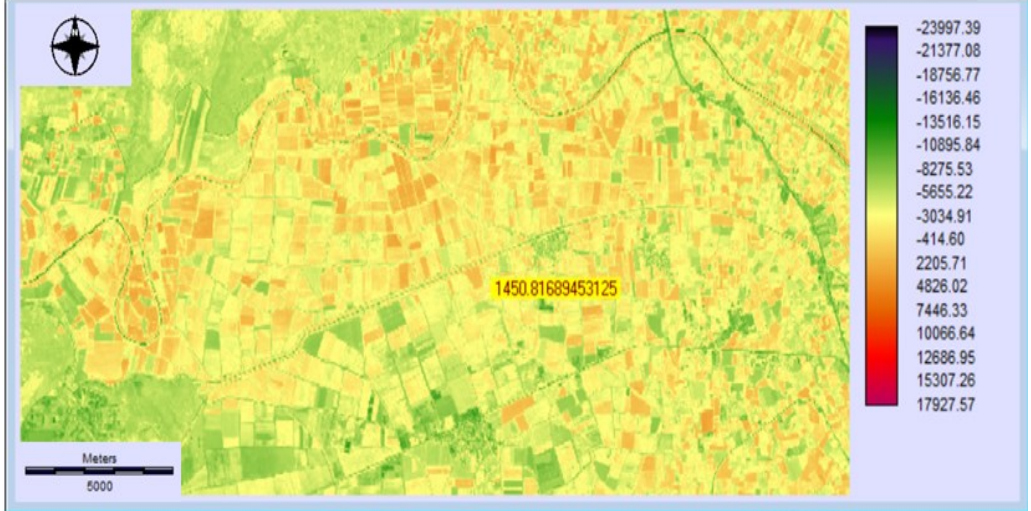

Sekil 6. Menemen Ovası misır verim haritası.

Figure 6. Yield map of maize on the Menemen Plain. 
Çizelge 4. Üretici parsellerine ait veriler.

Table 4. The data of farmer's plots.

\begin{tabular}{|c|c|c|c|c|c|c|c|}
\hline $\begin{array}{l}\text { S. No } \\
\text { Item } \\
\mathrm{Nu}\end{array}$ & $\begin{array}{l}\text { Üretici } \\
\text { Farmer }\end{array}$ & $\begin{array}{l}\text { Çeşit } \\
\text { Cultivar }\end{array}$ & $\begin{array}{l}\text { Ekim zaman1 } \\
\text { Sowing date }\end{array}$ & $\begin{array}{l}\text { Bitki sıklığ } 1 \\
\left(\text { adet } \mathrm{da}^{-1}\right) \\
\text { Plant density }\end{array}$ & $\begin{array}{l}\text { Ort. Verim } \\
\left(\mathrm{kg} \mathrm{da}^{-1}\right) \\
\text { Mean yield }\end{array}$ & $\begin{array}{l}\text { Potansiyel } \\
\text { verim } \\
\left(\mathrm{kg} \mathrm{da}^{-1}\right) \\
\text { Potential } \\
\text { yield }\end{array}$ & $\begin{array}{l}\text { Mahalle } \\
\text { Neighborhood }\end{array}$ \\
\hline 1 & Üretici 1 & D6980 & 25 Nisan & 8333 & $1300-1400$ & 1340 & Çavuş \\
\hline 2 & Üretici2 & D6980 & 20,25 Nisan & 10000 & 1200 & 1560 & Çavuş \\
\hline 3 & Üretici 3 & D6980 & 20,25 Nisan & 10000 & 1200 & 1560 & Çavuş \\
\hline 4 & Üretici 4 & D6630 & 24 Nisan & 9090 & $1300-1500$ & 1500 & Çavuş \\
\hline 5 & Üretici 5 & D6980 & 20,25 Nisan & 10000 & 1200 & 1560 & Yanık \\
\hline 6 & Üretici 6 & D6980 & 20,25 Nisan & 10000 & 1200 & 1560 & Yanık \\
\hline 7 & Üretici 7 & HektaşD24 & 28 Nisan & 10000 & 1200 & 1550 & Yanık \\
\hline 8 & Üretici 8 & LG & 20 Nisan & 8333 & $1200-1300$ & 1440 & Yanık \\
\hline 9 & Üretici 9 & D6698 & 5,20,25 Nisan & 9090 & $800-1500$ & $1490-1500$ & Türkelli \\
\hline 10 & Üretici 10 & Pioneer & 25 Nisan & 9090 & $1000-1300$ & 1500 & Türkelli \\
\hline 11 & Üretici 11 & 6980 & 28 Mart, 12 Nisan & 8500 & 1300,1650 & $1470-1450$ & Türkelli \\
\hline 12 & Üretici 12 & D6698 & 21 Nisan & 8000 & 1450 & 1410 & Menemen \\
\hline 13 & Üretici 13 & D6698 & 10 Nisan & 8000 & 1400 & 1410 & Menemen \\
\hline 14 & Üretici 14 & D6633 & 24 Nisan & 7300 & 1100 & 1350 & Çavuş \\
\hline 15 & Üretici 15 & LG30692 & 24 Mart & 8500 & 1300 & 1470 & Çavuş \\
\hline 16 & Üretici 16 & P6698 & 5 Mayıs & 8000 & 1400 & 1440 & Türkelli \\
\hline 17 & Üretici 17 & Pioneer & 6 Mayıs & 10000 & 1000 & 1510 & Türkelli \\
\hline 18 & Üretici 18 & LG & 5 Nisan & 10000 & 1400 & 1550 & Yanık \\
\hline 19 & Üretici 19 & D6980 & 24 Nisan & 9500 & 1400 & 1530 & Türkelli \\
\hline 20 & Üretici 20 & D6630 & 25 Nisan & 8333 & 1500 & 1440 & Yanık \\
\hline 21 & Üretici 21 & LG & 2 Mayıs & 9090 & 1100 & 1520 & Musabey \\
\hline 22 & Üretici 22 & P2105 & 21, 27 Nisan, 10 Mayıs & 8000 & 1150 & $\begin{array}{l}1410-1430- \\
1400\end{array}$ & Menemen \\
\hline
\end{tabular}

\section{TARTIŞMA}

Araştırmada Göktürk-2 uydu görüntüsü sınıflandırma sonuçlarının sınıflama genel doğruluğu \%86,7 ve Kappa indeksi \%73,3 olarak hesaplanmıştır. Sinıflama genel doğruluğu, üretilen harita üzerindeki sinif bilgisi ile yer bilgisi arasındaki uyumu göstermektedir. Tarımsal üretimde sinıflama doğruluğunun \%85 olmas1 genel olarak yeterli görülmekle birlikte, ekili alanların belirlenmesinde $\% 15$ oranındaki hata payı gıda güvenliği yönetimi veya piyasaları yönetmek için azaltılmalıdır (Gallego ve ark., 2010). Kappa değerinin $>0,80$ olması güçlü bir uyum olduğuna, 0,40- 0,80 arasında olmas1 ise orta derecede bir uyum olduğuna işaret etmektedir (Jensen, 2016). Misır alanlarını aynı yöntemle sınıflandıran Yang ve ark., (2007) Texas’ta 2,8 m çözünürlüğe sahip çok bantlı Quickbird uydu görüntüleriyle bitki örtüsünü \%83,6 genel doğrulukla sınıflandırmışlardır. Ormeci ve ark., (2010) Şanlıurfa'da misır ve pamuk ekim alanlarını segment tabanlı olarak SPOT 5 uydu görüntüsü üzerinde $\% 88,60$ genel doğruluk ve \%83,85 Kappa değeri ile sınıflandırmışlardır. Yine,
Zhenong ve ark., (2019) tarafindan Tanzanya'da $\% 79$, Kenya'da \%63 genel doğruluğa ulaşılmıştır. $\mathrm{Bu}$ araştırma kapsamında NDVI ve misır tane verimi ilişkisinin (R) değeri 0,88 olarak bulunmuștur. Bir meta analiz çalışmasında NDVI ve mısır verimi arasındaki ilişkiyi gösteren (R) değerini ABD'de yapılan bir çalışma için 0,94; bir Güney Afrika ülkesi olan Esvatin Krallığı'nda yapılan çalışmalarda ise 0,$71 ; 0,78$ ve 0,83 olarak bildirildiği görülmektedir (Huang ve Han, 2014).

Misır dane verimi ile Göktürk-2 uydu görüntüsünden elde edilen vejetasyon indeksi (NDVI) arasında 2020 yılında 0,01 hata düzeyinde ve $R^{2}=0,77$ değeri bulunmuştur. Schultes ve ark. (2013) yaptıkları çalışmada mısır verimi ile mısır bitkisinin toprağı kaplama yüzdesi arasında 0,01 hata düzeyi ve $\mathrm{R}^{2}=0,56$ değerinde tespit edilmiştir. Ferencz ve ark. (2004) Macaristan'da yaptıkları bir çalışmada NOAA uydu verisiyle elde edilen "genel birleştirilmiş verim indeksi" ile parsel bazlı mısır verimi arasındaki tahmin ilişkisi $\mathrm{R}^{2}=0,75$ olarak belirlenmiştir. 
Literatürde benzer çalışmalarda üretici parsellerinin toplam verimleri ile uydu verilerinden elde edilen vejetasyon indeksleri kullanılarak bölgesel verimlilik incelenmiştir (Schultes ve ark., 2013; Battude ve ark., 2016 ve Satir ve Berberoglu, 2016). Araștırma bulgularına göre, Hybrid-Maize bitki modeli ile yapılan verim tahminleri üretici parsellerinden alınan ortalama verimlere göre istatistiksel olarak daha fazla bulunmuştur. Bu nedenle, bu çalışmada bölge verimlerinin değerlendirilmesinde NDVI indeksi ile üretici parsel ortalama verimleri yerine gözlem parselinden ölçülen verim değerleri kullanılmıştır. $\mathrm{Bu}$ sayede, bitki modeli ile hesaplanan potansiyel verim değerleri ile gerçek verim değerlerinin karşılaştırılabileceği ve parsel bazlı değişimlerin incelenmesinde kullanılabileceği sonucuna ulaşılmıştır.

\section{SONUÇ}

$\mathrm{Bu}$ araştırmada uydu görüntüsünden elde edilen vejetasyon indeksi- verim ilişkisi incelenmiş, Hybrid-Maize bitki modelinin bölge için başarısı test edilmiş ve uydu verisi kullanılarak tane misır ekili alanların belirlenmesinde görüntü sınıflandırma başarısı değerlendirilmiştir. Uydu görüntüsü aracılığıyla ekim alanlarının belirlenmesi bölgede üretim miktarı, verim ve dağılımının tahmin edilmesi açısından önemlidir. $\mathrm{Bu}$ bakımdan öne sürülen yöntemin üretim planlamasının yapılabilmesine ve doğal kaynakların daha etkin kullanılmasına

\section{LITTERATÜR LİSTESI}

Anonim. 1971. Menemen Ovası Temel Toprak Etüdü. Toprak Su Genel Müdürlüğü Toprak ve Etüd Haritalama Dairesi Raporları, Seri No: 24, Ankara.

Anonim. 2020. Meteoroloji Genel Müdürlüğü, Resmi istatistikler. www.mgm.gov.tr/veridegerlendirme/il-veilceler-istatistik, (Erişim tarihi: 31.10. 2020).

Anonim. 2021. https://biruni.tuik.gov.tr/medas/?kn=92\& locale $=\operatorname{tr}($ Erişim tarihi 27.4.2021).

Arslan, İ. 2019. Python ile Veri Bilimi. Pusula 20 Teknoloji ve Yayıncılık A.Ş. İstanbul.

Battude, M., A. Bitar, D.Morin, J.Cros, M. Huc, C.M. Sicre, V. Dantec, and V. Demarez. 2016. Estimating maize biomass and yield over large areas using high spatial and temporal resolution Sentinel-2 like remote sensing data. Remote Sensing of Environment. 184. 668-681. olanak sağlayacağı öngörülmektedir. Literatürde verimliliğin değerlendirildiği çalışmalarda uydu görüntülerinden elde edilen vejetasyon indeksi ile üretici parsellerinin ortalama verimleri arasında bir bağıntı kurularak verim tahmini yapılırken, bu araştırmada gözlem parselinden elde edilen ölçüm değerleri kullanılmıştır. Bu kapsamda yapılan karş1laştırmalar sonucunda elde edilen bulgular kontrollü bir ortam olan gözlem parselinden elde edilen verim değerlerinin daha geniş alanlardaki üretim parsellerinde yapılan üretimin değerlendirilmesinde kullanılabileceğini göstermektedir. Hybrid-Maize gibi bitki modellerinin kullanılması üretim ortamında üretime etki eden faktörlerin daha iyi değerlendirilmesine, bölgenin üretim potansiyeli ile gerçekleşen verimler arasındaki farkın anlaşılmasına yardımcı olmaktadır. $\mathrm{Bu}$ şekilde üretim faaliyetlerinin iyileştirilmesi ve gida güvencesinin sağlanması mümkün olabilecektir. Araştırma sonuçlarının bölgenin verim tahminine yönelik hızl, güvenilir ve tekrarlanabilir bir inceleme ortamı ve yöntemi sağlayarak ürün izleme uygulamalarına katkıda bulunacağı düşünülmektedir.

\section{TEŞEKKÜR}

$\mathrm{Bu}$ araştırma T.C. Tarım ve Orman Bakanlığı, Tarımsal Araştırmalar ve Politikalar Müdürlüğü tarafindan TAGEM/TSKAD/16/A13/P08/01/A.P.1 proje numarası ile desteklenmiştir.

Egberth, M., and M. Nilsson. 2010. "KNN-Sweden--Current map data on Swedish forests." In Proceedings ForestSat 2010: Operational tools in forestry using remote sensing techniques. 265-267.

Ferencz, Cs., P. Bogna, J. R. Lichtenberger, D. Hamar, G. Tarcsai, G. Timar, R. G. Molna, P. Pasztor, Sz. Steinbach, B. Szekely, O. E. Ferencz, and I. FerenczArkos. 2004. Crop yield estimation by satellite remote sensing Int. J. Remote Sensing Vol. 25, No. 20: 41134149.

Gallego, J., E. Carfagna, and B. Baruth. 2010. Accuracy, objectivity and efficiency of remote sensing for agricultural statistics pp. 202-205. In: Benedetti, R., Bee, M., Espa, G., Piersimoni, P. (Ed.’s ) Agricultural Survey Methods. John Wiley \& Sons Ltd., Wiltshire., UK.

Huang, J., and D. Han. 2014. Meta-analysis of influential factors on crop yield estimation by remote sensing. International Journal of Remote Sensing, Vol. 35, No. 6: 2267-2295, http://dx.doi.org/10.1080/01431161. 2014.890761 (Erişim tarihi: 01/04/2021). 
Jensen, J. R. 2016. Introductory Dijital Image Processing: A Remote Sensing Perspective, 4th Ed. Pearson.

Jones, H. G., and R. A. Vaughan. 2010. Remote Sensing of Vegetation Principles, Techniques and Applications. Oxford University Press, New York, US.

Konuk, A. 2016. Coğrafi Bilgi Sistemleri için Temel İstatistik. s. 72. Anadolu Üni. Yay. No: 2326. Eskişehir.

MGM. 2020. Meteoroloji Genel Müdürlüğü, Resmi istatistikler. www.mgm.gov.tr/veridegerlendirme/il-veilceler-istatistik, (Erişim tarihi: 31.10. 2020).

Oğuz, C. ve Z. Karakayacı. 2017. Tarım Ekonomisinde Araştırma ve Örnekleme Metodolojisi. Atlas Akademi Yayınları. Konya.

Ok, A. Ö. 2017. Sınıflandırma- İleri Teknikler s.171-197. F. Sunar (Ed.). Dijital Görüntü İşleme. Anadolu Üni. Yay. No: 3658. Eskişehir.

Ormeci, C., U.Alganci, and E. Sertel, 2010. Identification of crop areas using SPOT - 5 Data. TS $4 \mathrm{H}-$ Remote Sensing and Imagery I. Facing the Challenges Building the Capacity Sydney, Australia, 11-16 April 2010. Available at: https://www.researchgate.net/ publication/256454210 (Erişim tarihi: 08.03. 2021).

Ozdarici Ok, A.,and Z. Akyurek. 2012. A Segment-based approach to classify agricultural lands by using multitemporal optical and microwave data. International Journal of Remote Sensing, 33: 22, 7184-7204

Sarı, M., N. K. Sönmez ve M. Yıldıran. 2007. Pamuk bitkisinin kantitatif yansıma özelliklerinin ve alansal dağılımının uydu verileri ile belirlenmesi. Akdeniz Üniversitesi Ziraat Fakültesi Dergisi, 20(1): 1-10.

Satir, O., ve S. Berberoglu. 2016. Crop yield prediction under soil salinity using satellite drived vegetation indices. Field Crops Research 192: 134-143.

Schultes, U., J. Timsina, J. M. Herrera, and A. Mcdonald. 2013. Mapping field-scale yield gaps for maize: An example from Bangladesh. Field Crops Research 143: 143-156.
Steinberg, S. L., and J. S. Steinberg. 2015. GIS Research Methods Incorporation Spatial Perspectives. Esri Press, Redlands, California, US.

Teke, M., C. Demirkesen, O. Haliloğlu ve E. İmre. 2016. Göktürk-2 uydusunun bağıl ve mutlak çapraz radyometrik kalibrasyonu. Harita Dergisi 155: 32-52.

Turker, M., and A. Ozdarici. 2011. Field-based crop classification using SPOT4, SPOT5, IKONOS and QuickBird imagery for agricultural areas: a comparison study. International Journal of Remote Sensing, 32:24: 9735-9768.

Yang H.S., A. Dobermann, J.L. Lindquist, D. T. Walters, T. J. Arkebauer, and K. G. Cassman. 2004. Hybridmaize-a maize simulation model that combines two crop modeling approaches. Field Crops Research 87: 131-154.

Yang, C., J. H. Everitt, R. S. Fletcher, and D. Murden. 2007. Using high resolution QuickBird imagery for crop identification and area estimation, Geocarto International, 22:3, 219-233 (Erişim 04.04.2021).

Yang, H. S., A. Dobermann, K. G. Cassman, D. T. Walters, and P. Grassini. 2016. Hybrid-Maize (ver. 2016). A Simulation Model for Corn Growth and Yield. Nebraska Cooperative Extension, University of Nebraska-Lincoln, Lincoln, NE.

Yorulmaz, Ö. 2016. Dayanıklı İstatistiksel Yöntemler ve R Uygulamaları. Beta Basım Yayım Dağıtım A.Ş. İstanbul.

Zhenong, J., G. Azzaria, C.Youa, S. D.Tommasoa, S.Aston, M. Burkea, and D. B. Lobella. 2019. Smallholder maize area and yield mapping at national scales with Google Earth Engine. Remote Sensing of Environment 228: 115-128. 